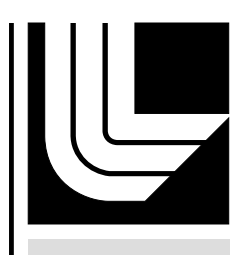

LAW RENCE LIVERMORE N A T IO N A L LABORATORY

Constructing a large-scale 3D Geologic Model for Analysis of the Non-Proliferation Experiment

J. Wagoner, S. Myers

April 17, 2008 
This document was prepared as an account of work sponsored by an agency of the United States government. Neither the United States government nor Lawrence Livermore National Security, LLC, nor any of their employees makes any warranty, expressed or implied, or assumes any legal liability or responsibility for the accuracy, completeness, or usefulness of any information, apparatus, product, or process disclosed, or represents that its use would not infringe privately owned rights. Reference herein to any specific commercial product, process, or service by trade name, trademark, manufacturer, or otherwise does not necessarily constitute or imply its endorsement, recommendation, or favoring by the United States government or Lawrence Livermore National Security, LLC. The views and opinions of authors expressed herein do not necessarily state or reflect those of the United States government or Lawrence Livermore National Security, LLC, and shall not be used for advertising or product endorsement purposes.

This work performed under the auspices of the U.S. Department of Energy by Lawrence Livermore National Laboratory under Contract DE-AC52-07NA27344. 


\title{
Constructing a large-scale 3D Geologic Model for Analysis of the Non- Proliferation Experiment
}

\author{
Wagoner, Jeffrey L. and Myers, Stephen C. \\ Lawrence Livermore National Laboratory \\ Atmospheric, Earth and Energy Division \\ P.O. Box 808, Livermore, CA 94551
}

\section{ABSTRACT}

We have constructed a regional 3D geologic model of the southern Great Basin, in support of a seismic wave propagation investigation of the 1993 Nonproliferation Experiment (NPE) at the Nevada Test Site (NTS). The model is centered on the NPE and spans longitude $-119.5^{\circ}$ to $-112.6^{\circ}$ and latitude $34.5^{\circ}$ to $39.8^{\circ}$; the depth ranges from the topographic surface to 150 $\mathrm{km}$ below sea level. The model includes the southern half of Nevada, as well as parts of eastern California, western Utah, and a portion of northwestern Arizona. The upper crust is constrained by both geologic and geophysical studies, while the lower crust and upper mantle are constrained by geophysical studies. The mapped upper crustal geologic units are Quaternary basin fill, Tertiary deposits, pre-Tertiary deposits, intrusive rocks of all ages, and calderas. The lower crust and upper mantle are parameterized with 5 layers, including the Moho. Detailed geologic data, including surface maps, borehole data, and geophysical surveys, were used to define the geology at the NTS. Digital geologic outcrop data were available for both Nevada and Arizona, whereas geologic maps for California and Utah were scanned and hand-digitized. Published gravity data ( $2 \mathrm{~km}$ spacing) were used to determine the thickness of the Cenozoic deposits and thus estimate the depth of the basins. The free surface is based on a $10 \mathrm{~m}$ lateral resolution DEM at the NTS and a 90m lateral resolution DEM elsewhere. Variations in crustal thickness are based on receiver function analysis and a framework compilation of reflection/refraction studies. We used Earthvision (Dynamic Graphics, Inc.) to integrate the geologic and geophysical information into a model of $\mathrm{x}, \mathrm{y}, \mathrm{z}, \mathrm{p}$ nodes, where $\mathrm{p}$ is a unique integer index value representing the geologic unit. For seismic studies, the geologic units are mapped to specific seismic velocities. The gross geophysical structure of the crust and upper mantle is taken from regional surface-wave studies. For regional seismic simulations we convert this realistic geologic model into elastic parameters. Upper crustal units are treated as seismically homogeneous while the lower crust and upper mantle 
are parameterized by a smoothly varying velocity profile. In order to mitigate spurious reflections, the lower crust and upper mantle are treated as velocity gradients as a function of depth.

\section{INTRODUCTION}

Fundamental to geologic characterization is the compilation of spatial distributions of lithology and physical properties. Geoscientists have generally relied on two-dimensional visualizations for analyzing geological data. Traditional geologic maps contain projected information about the subsurface in the form of strikes, dips, fold axes, fault traces, etc., as well as implicit information like the distribution and apparent thickness of units and contacts on the land surface. Geological maps typically include a crosssection that provides an interpretation of the subsurface. But because of the complexity of the spatial relationships, a three-dimensional model of geology is better suited for integrating different types of data, providing a more realistic characterization of a site than a two-dimensional view. Being able to easily manipulate a large, complex data set provides the geoscientist with the opportunity to detect and visually analyze spatial correlations between different types of data, which leads to an increased understanding of the subsurface.

With technological advances, there has been an increased interest in constructing complete three-dimensional models of geology. Regional-scale models remain, however, limited in their development, due in part to the challenges presented by construction of high-resolution grids that depict structural, lithologic, and stratigraphic features where there are sparse data. Three-dimensional models can be very well constrained in areas where seismic and borehole data are available. The process is to revise the 3D model as new data are progressively added or as our interpretative understanding of the geology evolves. New data are often slowly acquired over time during which this "living" model evolves.

Software is available for interpolating and projecting geologic data into the subsurface. Map-derived data, along with geophysical, borehole and other data, can now be assembled into a realistic 3D model as a set of surfaces, with the volumes defined by those surfaces. Earthvision, developed by Dynamic Graphics Inc., is a 3D model-building and visualization software package, with which precise 3D models can be quickly created and updated. 
A regional 3D geologic model of the southern Great Basin was constructed in support of a seismic wave propagation investigation of the 1993 Nonproliferation Experiment (NPE), a 1 kiloton chemical explosion at the Nevada Test Site (NTS). This model is centered on the NPE (Figure 1) and ranges from longitude $-119.5^{\circ}$ to $-112.6^{\circ}$, latitude $34.5^{\circ}$ to $39.8^{\circ}$, and a depth from the surface down to $150 \mathrm{~km}$. The model includes the southern half of Nevada, as well as parts of eastern California, western Utah, and a portion of northwestern Arizona (Figure 1).

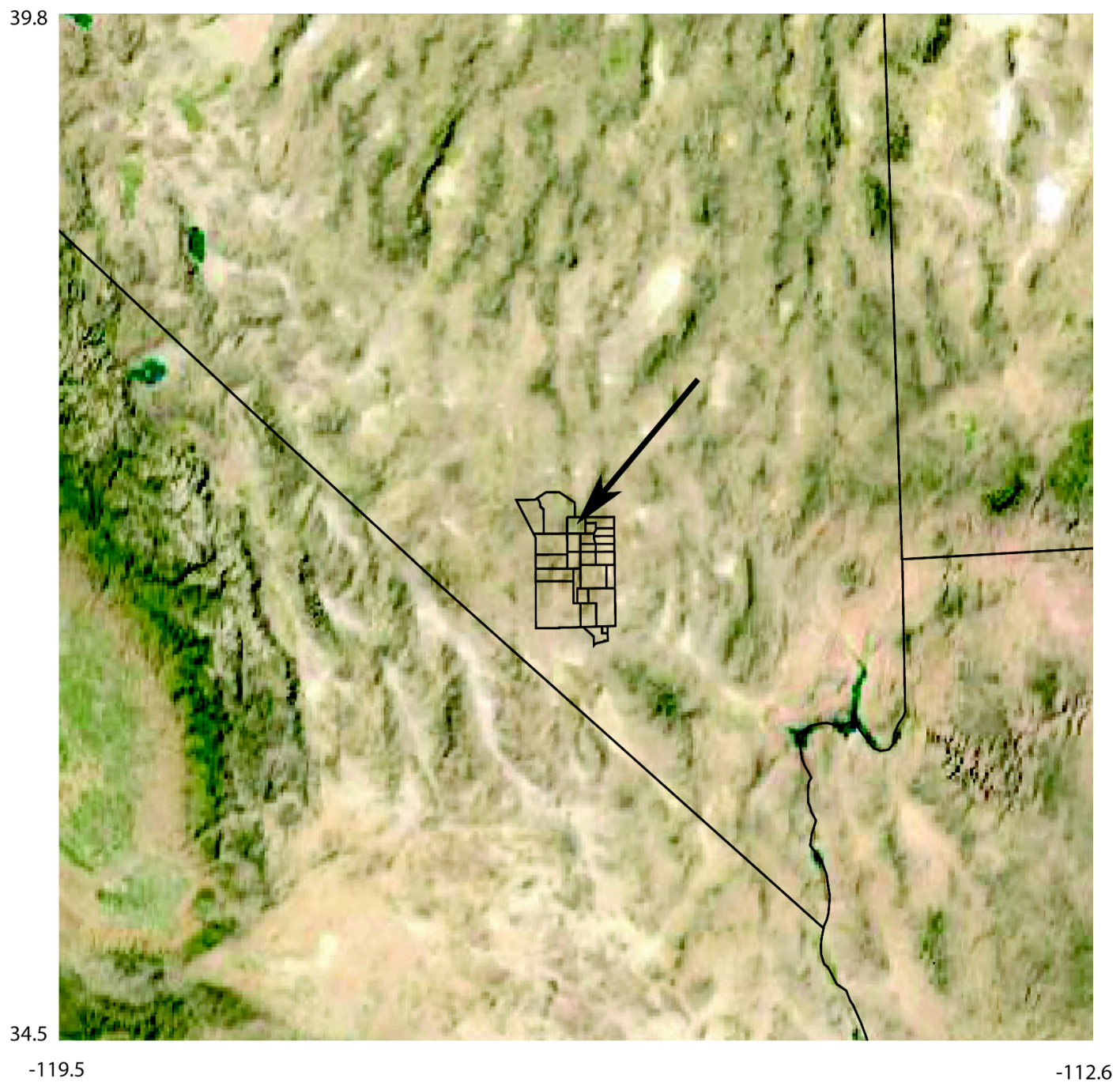

Figure 1. Satellite photo showing the range of the Southern Great Basin geologic model, with the state boundaries, as well as the location of the Nevada Test Site. The black arrow indicates the approximate location of the NPE. 


\section{DATA and METHODS}

Most of the geologic information that goes into this model is defined by surface outcrops. Because of the large scale of this model, it would be difficult to focus on the fine details of the geology. It is more efficient to start with the surficial outcrops of the mappable geologic formations and attempt to define structural surfaces for these units based on the available outcrop data. Polygon data that defined the extent of surficial exposures were available for much of Nevada from the UNR Keck online database (http://keck.library.unr.edu/data/gbgeosci/gbgdb.htm). These polygons defined the spatial distribution (xy only) of the mapped units that were used in the model. Similar digital data were also available for the state of Arizona (AGS DI-08, 1998). Unfortunately, digital data were not available for Utah and California. For these states, we scanned existing geologic maps (mainly 1:250000). Polygons were hand digitized for the pertinent mappable units for these states.

Detailed geologic data, including geologic maps, borehole data, and geophysical surveys, were available to define the geology at the NTS and in the Las Vegas Basin. The geologic data are much more concentrated at the NTS, a result of the historic underground nuclear test program. More than 1300 boreholes were drilled in this area, and most of these holes were logged with samples and geophysical logs. Stratigraphic data are available for most of the boreholes at NTS (Wagoner and Richardson, 1986). Numerous geophysical surveys, including gravity, magnetic, and seismic reflection, were also run across the NTS and these surveys helped constrain the geologic framework of this area (Burkhard, 1983). These data are archived at Lawrence Livermore National Laboratory.

The Las Vegas Basin is not as well characterized as the NTS, but there is substantial information available as compared to most parts of the regional model. The USGS fielded a gravity survey across the basin, and these data help define the geometry of the basement structure for the basin (Langenheim, et. al, 1998). Additional subsurface stratigraphic and structural data are reported by Taylor et. al., (2008).

Published gravity data ( $2 \mathrm{~km}$ spacing) were used to determine the thickness of the Cenozoic deposits and thus constrain the depth of the basins (Saltus and Jachens, 1995). These data were critical to define the depth of the basins 
in the regional model, since borehole data were not readily available for all basins.

The first step in building this model was to define the node structure to create a topographic surface. The free surface is based on a $10 \mathrm{~m}$ lateral resolution DEM at the NTS and a 90m lateral resolution DEM elsewhere. Since the range of this model is large, we had to settle for a fairly coarse grid spacing. Both $10 \mathrm{~m}$ and $30 \mathrm{~m}$ DEM are available in the study area, but a DEM with this type of grid spacing would be too large for both the software and the hardware. We decided to use a 90m DEM to build the topographic surface for the range of the model; these data were downloaded from a USGS website. A more detailed 10m DEM was incorporated for the $20 \mathrm{~km}$ radius around ground zero, and this provided much more detailed topography near the explosion.

We converted the topographic DEM into a 2D grid within Earthvision. This binary grid was then converted to an ASCII data file which was subsequently decimated to create a manageable data file. These data were then used to define the top surface of the individual mappable geologic units. As each outcrop is defined by a polygon, the top of each unit will be defined by the elevation data points within that polygon. An Earthvision algorithm was used that would fill in each polygon with elevation points from the ASCII data file derived from the 2D grid. This process resulted in a single file for each of the mappable units. Each of these files represented the structural top of that unit.

\section{MAPPABLE UNITS}

There are numerous mappable geologic formations on the existing geologic maps in the Great Basin, but for the purposes of this investigation, and because of the very large area of the model, it was decided to keep the number of mappable units at a minimum (Figures 2 and 3). This is especially true since we are primarily concerned with variations in physical properties such as seismic velocity and density. In many cases, mappable formations of different ages will have very similar physical properties and are therefore combined into a single mappable unit for the purposes of this type of investigation. 


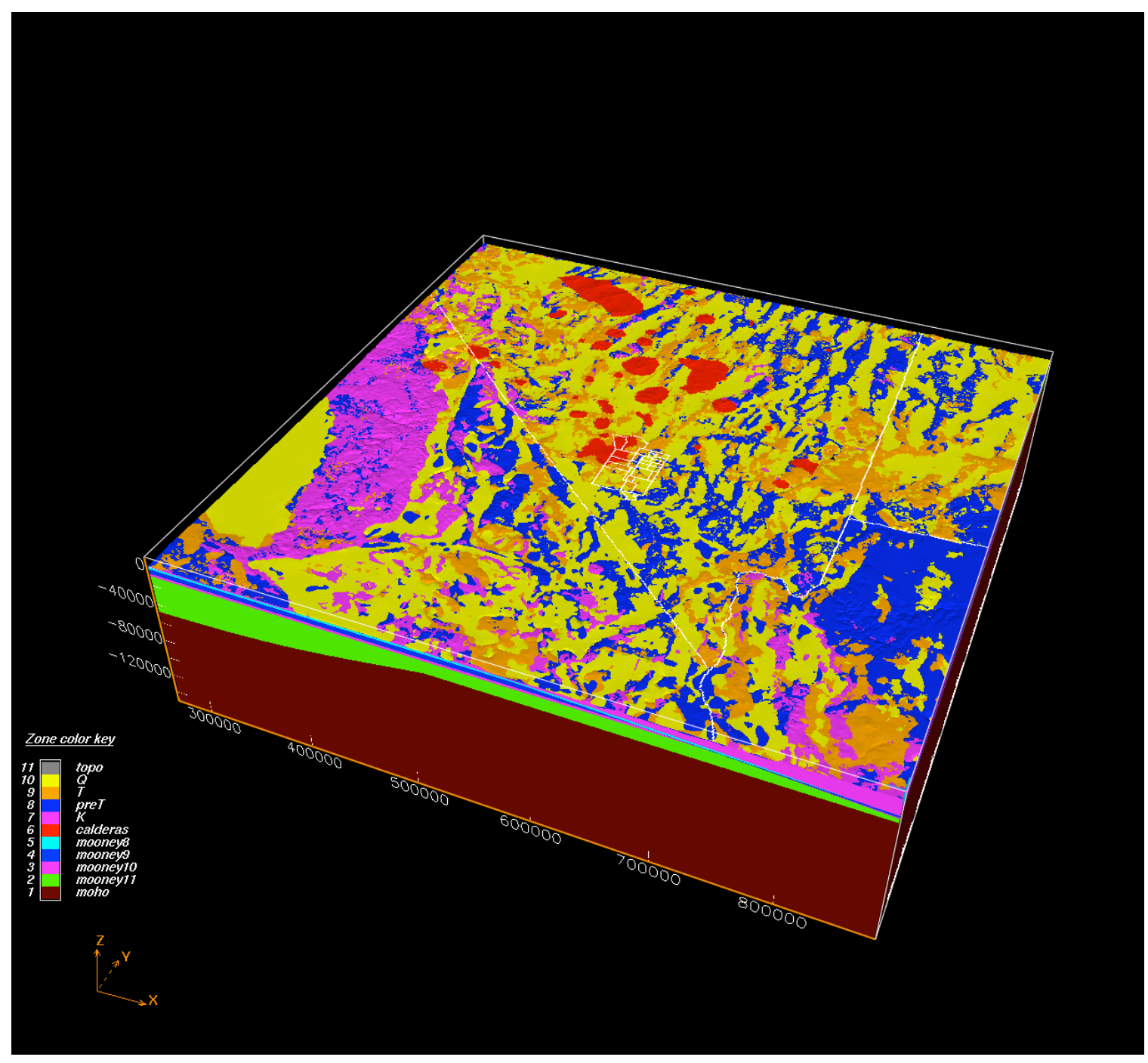

Figure 2. Full 3D geologic model of the Southern Great Basin; there is no vertical exaggeration (map projection is UTM zone 11, meters).

The upper crust is constrained by both geologic and geophysical studies, while the lower crust and upper mantle are constrained by geophysical studies. The lower crust and upper mantle are parameterized with 5 layers, including the Moho. The following mappable units are defined for the upper crust:

Quaternary deposits-mainly nonmarine alluvial and lacustrine sediments

Tertiary deposits-mainly volcanics and nonmarine clastic sediments Pre-Tertiary rocks-mainly marine sediments Intrusive rocks-various ages 


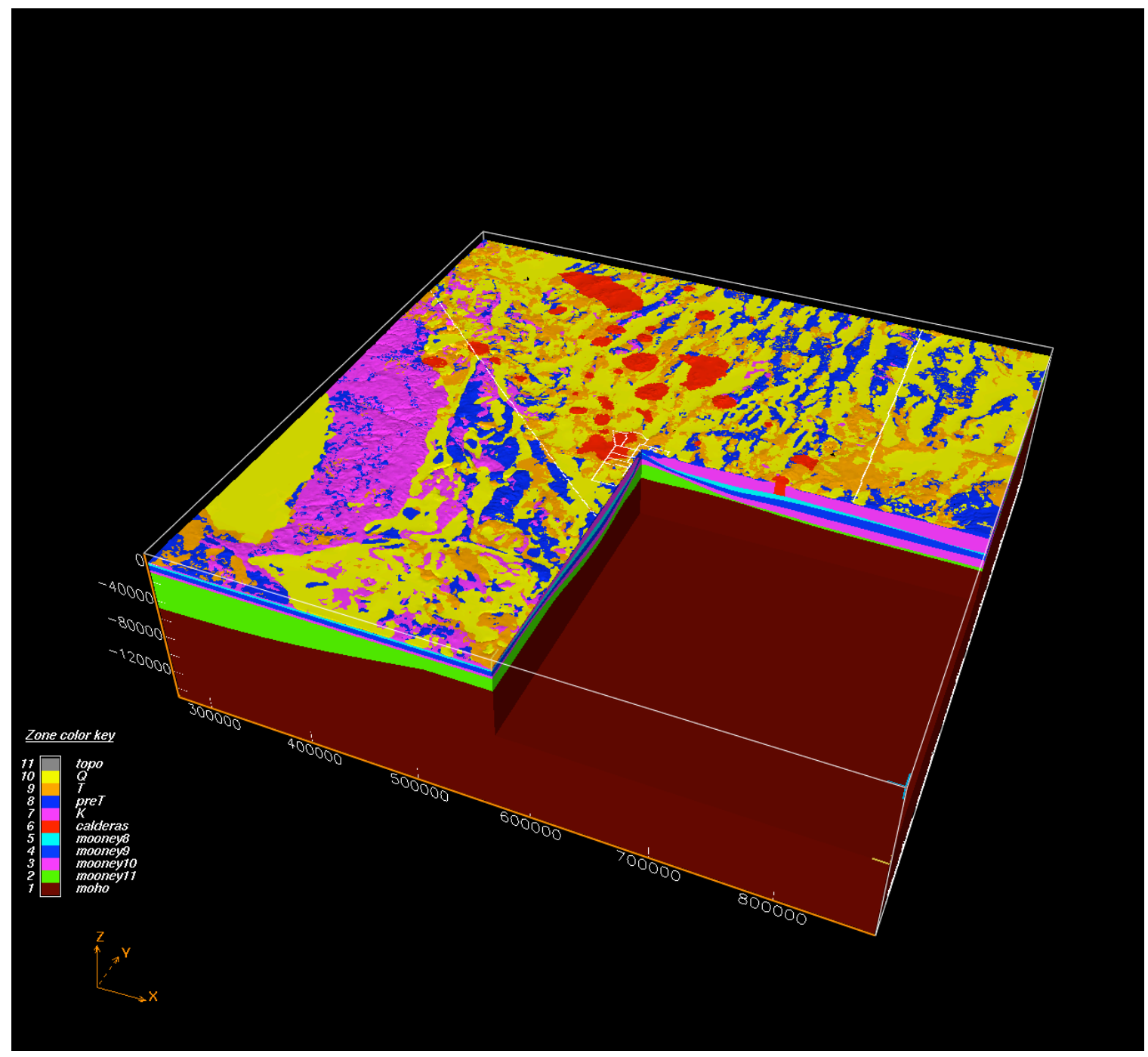

Figure 3. Full 3D geologic model of the Southern Great Basin, with a chair view showing some of the internal variations within the model. Map projection is UTM zone 11 meters.

The Quaternary deposits are represented mainly by nonmarine sedimentary basin fill, although Quaternary volcanics are also included. By definition, the top of these deposits is at the topographic surface of the model. Because of the paucity of data, the contact of the Quaternary and Tertiary units is not locally precise in a model of this size, especially in the basins. The Tertiary deposits are comprised of both nonmarine sediments and volcanics. As with the Quaternary units, these sediments can be either fluvial or lacustrine in origin. There is a wide variety of volcanic deposits represented in the 
Tertiary section, ranging from relatively weak nonwelded tuffs to very strong welded ash-flow tuffs and lava flows. The calderas are modeled as "holes" in the model and filled in with volcanic and volcaniclastic material. The boundaries of the calderas are defined by polygons from the UNR Keck database and confirmed by existing geologic maps.

The pre-Tertiary rocks are dominantly Paleozoic sedimentary rocks and these units, along with the intrusive rocks, represent the "bedrock" in the model. Published gravity data ( $2 \mathrm{~km}$ spacing) were used to determine the thickness of the Cenozoic deposits and thus constrain the depth of the basins and the structural top of the older formations. The lithologies range from carbonate to clastic and these rocks can be very strong with high seismic velocities. The intrusive rocks are represented by igneous intrusions. The chemistry of these rocks varies widely, but for the purposes of this study, that is not relevant. The intrusive rocks are generally strong with relatively high velocities, representing intrusions of all ages within the model area.

The gross geophysical structure of the crust and upper mantle is taken from regional surface-wave studies. Variations in crustal thickness are based on receiver function analysis and a compilation of reflection/refraction studies. We used Earthvision to integrate the geologic and geophysical information into a model of $\mathrm{x}, \mathrm{y}, \mathrm{z}, \mathrm{p}$ nodes, where $\mathrm{p}$ is an integer index representing the geologic unit. For regional seismic simulations we convert this realistic geologic model into elastic parameters. Upper crustal units are treated as seismically homogeneous. In order to mitigate spurious reflections, the lower crust and upper mantle are treated as velocity gradients as a function of depth.

\section{SUMMARY}

We have constructed a regional 3D geologic model of the southern Great Basin, in support of a seismic wave propagation investigation of the 1993 Nonproliferation Experiment at the Nevada Test Site. The model is centered on the NPE and ranges from the topographic surface to $150 \mathrm{~km}$ below sea level. The geologic model includes Quaternary basin fill, Tertiary deposits, pre-Tertiary deposits, intrusive rocks of all ages, and calderas. The lower crust and upper mantle are parameterized with 5 layers, including the Moho. We used Earthvision software to integrate the geologic and geophysical information into a grid model of $\mathrm{x}, \mathrm{y}, \mathrm{z}, \mathrm{p}$ nodes, where $\mathrm{p}$ is a unique integer index value representing the geologic unit. For seismic studies, the geologic 
units are mapped to specific seismic velocities. For regional seismic simulations we convert this realistic geologic model into elastic parameters. Upper crustal units are treated as seismically homogeneous while the lower crust and upper mantle are parameterized by a smoothly varying velocity profile. In order to mitigate spurious reflections, the lower crust and upper mantle are treated as velocity gradients as a function of depth.

\section{REFERENCES}

Burkhard, N. R., 1983, NTS Seismic reflection data and the problems thereof, Proceedings of the Monterey Containment Symposium, B. C. Hudson et al., eds., Los Alamos National Laboratory Report LA-9211-C, Vol. 1, pp. 339-341.

Chulick, G. S., and Mooney, W. D., 2002. Seismic structure of the crust and uppermost mantle of North America and adjacent oceanic basins: a synthesis. Bulletin of the Seismological Society of America, v. 92, no. 96, pp. 2478-2492.

Digital spatial data for the geologic map of Arizona, 1998. Arizona Geological Survey DI-08, v. 3.

Geologic atlas of California, California Division of Mines and Geology, 1958-1966, 1:250,000. Quadrangles used are Bakersfield, Death Valley, Fresno, Kingman, Los Angeles, Mariposa, Needles, San Bernardino, Trona, and Walker Lake.

Hintze, L. F., Willis, G. C., Laes, D. Y. M., Sprinkel, D. A., and Brown, K. D. 2000. Digital geologic map of Utah. M179DM.

Langenheim, V.E., Grow, J., Miller, J., Davidson, J.D., and Robison, E., 1998, Thickness of Cenozoic deposits and location and geometry of the Las Vegas Valley Shear Zone, Nevada, based on gravity, seismic-reflection, and aeromagnetic data: U.S. Geological Survey Open-File Report 98-576, 31 p.

Mooney, W. D., Laske, G., and Masters, T. G., 1998. Crust 5.1: A global model at $5^{\circ} \times 5^{\circ}$. Journal of Geophysical Research, v. 103, no. B1, pp. 727747. 
Patton, H.J., and S.R. Taylor, 1984. Q-structure of the basin and range from surface waves, Journal Geophysical Research, 89, no. B8, pp.6929-6940.

Saltus, R. W. and Jachens, R. C., 1995. Gravity and basin depth maps of the Basin and Range Province, Western United States, USGS GP-1012, scale $1: 2,500,000$.

Taylor, W. J., Carter, J., Luke, B., Snelson, C., and Wagoner, J. 2008. Development of Las Vegas Basin, Nevada, with implications for seismic hazards. Geological Society of America Abstracts with Programs, Vol. 40, No. 1, p. 72. Cordilleran Section and Rocky Mountain Section Joint Meeting (19-21 March 2008, Las Vegas, NV).

Wagoner, J. L. and Richardson, W., 1986. Stratigraphic contacts from drillholes at the Nevada Test Site. UCID-20790.

Zandt, G., Myers, S. C., and Wallace, T. C., 1995. Crust and mantle structure across the Basin and Range-Colorado Plateau boundary at $37^{\circ} \mathrm{N}$ latitude and implication for Cenozoic extensional mechanism. Journal of Geophysical Research, v. 100, no. B6, pp. 10529-10548. 